\title{
Anatomic Variations of the Median Nerve in the Carpal Tunnel: A Brief Review of the Literature
}

\author{
Median Sinirin Karpal Tüneldeki Anatomik Varyasyonlart: \\ Literatürün Kisa Bir Derlemesi
}

\author{
Emre DEMIRCAY ${ }^{1}$, Erdinc CIVELEK ${ }^{2}$, Tufan CANSEVER $^{2}$, Serdar KABATAS ${ }^{2}$, Cem YILMAZ \\ ${ }^{1}$ Baskent University, Faculty of Medicine, Department of Othopedics and Traumatology, Istanbul, Turkey \\ ${ }^{2}$ Baskent University, Faculty of Medicine, Department of Neurosurgery, Istanbul, Turkey \\ ${ }^{3}$ Baskent University, Faculty of Medicine, Department of Neurosurgery, Ankara, Turkey
}

Correspondence address: Emre DEMIRCAY / E-mail: emredemircay@hotmail.com

\begin{abstract}
Carpal tunnel syndrome (CTS) is a common focal peripheral neuropathy. Increased pressure in the carpal tunnel results in median nerve compression and impaired nerve perfusion, leading to discomfort and paresthesia in the affected hand. Surgical division of the transverse carpal ligament is preferred in severe cases of CTS and should be considered when conservative measures fail. A through knowledge of the normal and variant anatomy of the median nerve in the wrist is fundamental in avoiding complications during carpal tunnel release. This paper aims to briefly review the anatomic variations of the median nerve in the carpal tunnel and its implications in carpal tunnel surgery.
\end{abstract}

KEYWORDS: Median nerve, Anatomic variation, Carpal tunnel, Transverse carpal ligament

öz

Karpal tünel sendromu (KTS) sık görülen bir periferik nöropatidir. Karpal tünel basıncının artması median sinirin sıkışmasına ve kanlanmasının bozulmasına yol açar. Ağır vakalarda ve konservatif tedavinin yeterli olmadığı durumlarda cerrahi olarak transvers karpal ligamanın kesilmesi tercih edilir. Karpal tünelin gevşetilmesi sırasında komplikasyonlardan kaçınmak için median sinirin bu bölgedeki ayrıntılı anatomisinin ve varyasyonlarının iyi bilinmesi gereklidir. Bu derleme median sinirin karpal tüneldeki olası anatomik varyasyonlarını ve bunun karpal tünel cerrahisine etkilerini kısaca gözden geçirmek amacıyla yazılmıştır.

ANAHTAR SÖZCÜKLER: Median sinir, Anatomik varyasyon, Karpal tünel, Transvers karpal ligaman

\section{INTRODUCTION}

Entrapment of the median nerve in the carpal tunnel is one of the most common entrapment neuropathy syndromes in clinical practice $(3,20)$. The main causes of this syndrome include repetitive strain, wrist fracture, rheumatoid arthritis, a space-occupying lesion, dialysis-related amyloidosis, diabetes mellitus, and cases with no apparent cause $(27,33)$. Phalen GS found thickening of the synovium in most of the operative cases and concluded that thickening or fibrosis was the most common cause of the syndrome (29).

Anatomic variations of the median nerve are frequent and they are significant for wrist surgery particularly in the treatment of CTS. Surgical techniques with short incisions and endoscopic procedures demand a thorough knowledge of the anatomy and variations of the structures in the wrist.

\section{Surgical anatomy of carpal tunnel}

The flexor retinaculum and carpal tunnel: The flexor retinaculum is a strong ligament that forms the roof of the transverse carpal arch. Its main function is to serve as a flexor pulley at the wrist for the flexor tendons. It is attached to the pisiform, hamate, scaphoid, and trapezium, converting the palmar arch into the carpal tunnel. The carpal tunnel is a narrow fibro-osseous tunnel through which the median nerve passes with nine tendons (four flexor digitorum superficialis, four flexor digitorum profundus and flexor pollicis longus) and sometimes accompanied by persistent median artery (Figure 1). Carpal tunnel behaves like a closed compartment and maintains its own tissue fluid pressure levels (35). Anomalous elongation of the muscle bellies of the flexor digitorum superficialis, the palmaris longus, patent median artery, or a proximal origin of a lumbrical muscle may compress the contents of the carpal tunnel. The proximal wrist flexion crease identifies the proximal edge of the carpal tunnel and it ends at the base of the third metacarpal. Proximal portion of the flexor retinaculum is a direct continuation of the deep antebrachial fascia. The transverse carpal ligament represents the central portion of the flexor retinaculum. Distally is an aponeurosis between thenar and hypothenar muscles (7). (Figure 2). 


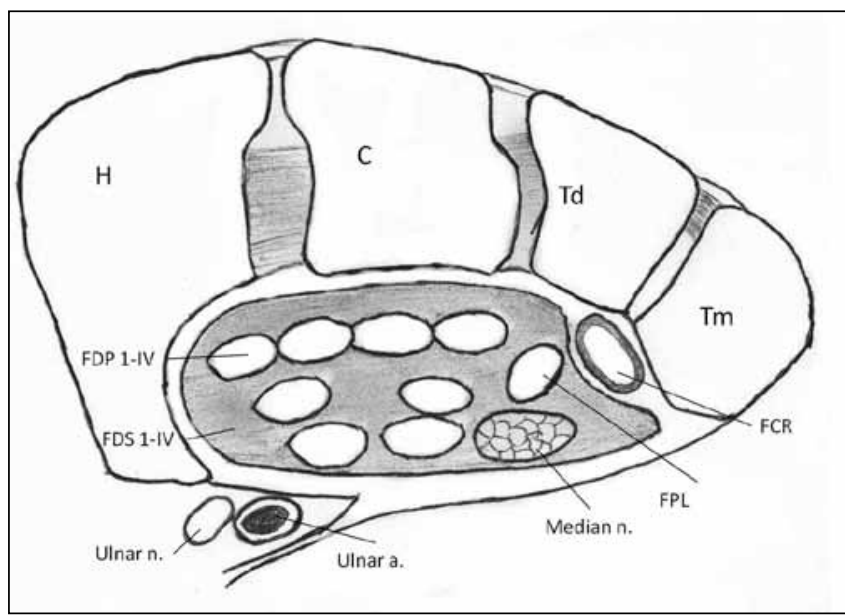

Figure 1: Axial section of the carpal tunnel through distal carpal row. FDS I - IV: flexor digitorum superficialis I to IV; FPL: flexor pollicis longus tendon; a: artery; n: nerve; FCR: flexor carpi radialis tendon; FDP I - IV: flexor digitorum profundus I to IV; H: hamate; C: capitate; Td: trapezoid; Tm: trapezium. Flexor carpi radialis tendon is in a separate compartment.

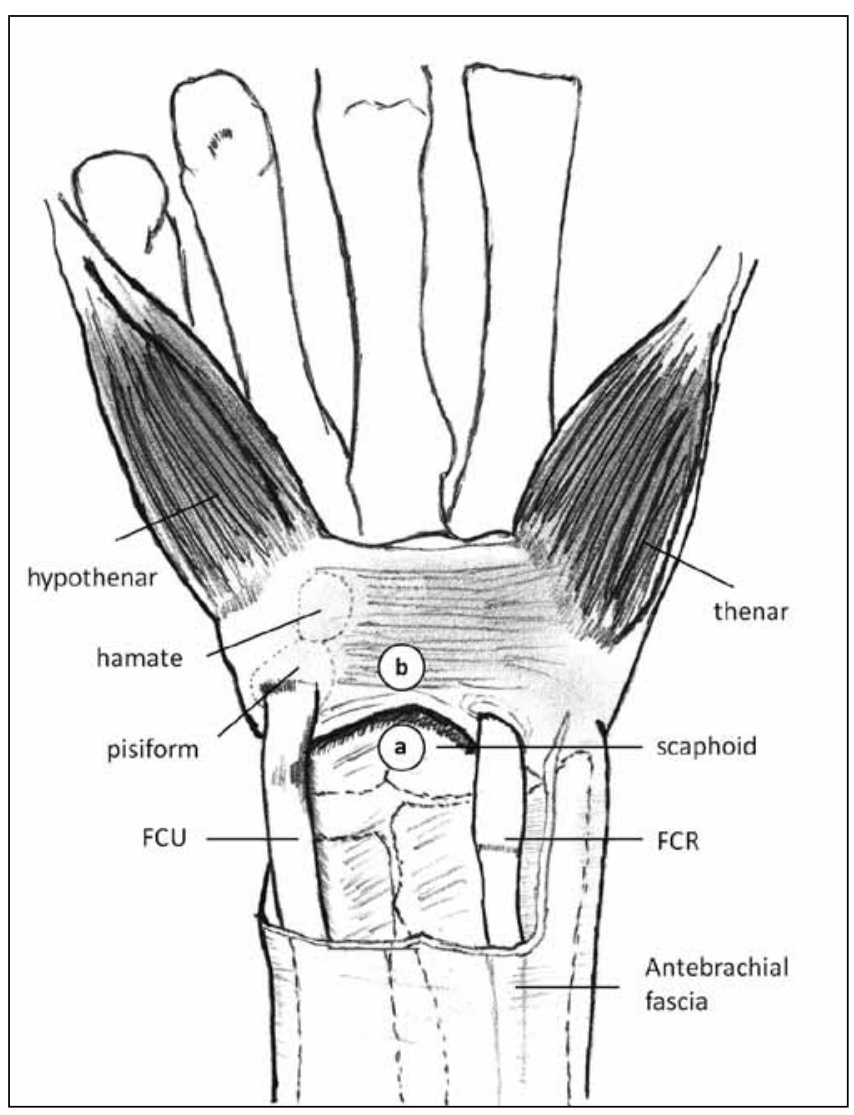

Figure 2: The flexor retinaculum and carpal tunnel. Proximal entrance into the carpal tunnel is shown between the tendons of flexor carpi ulnaris (FCU) and flexor carpi radialis (FCR), contents of the carpal tunnel are not shown (a). The thickest portion of the carpal ligament is at the level of hook of hamate (b); it ends at the level of carpometacarpal joints as a thinner structure.
Carpal tunnel width at the hook of hamate is narrowest, at the level of the hook of hamate with a mean of $20 \mathrm{~mm}$, approximately $2-2.5 \mathrm{~cm}$ distal to its most proximal margin. It is the thickest portion of the transverse carpal ligament. It expands to a mean width of $24-25 \mathrm{~mm}$ at its proximal and distal margins (7). This has been questioned through more recent studies. It was reported that neither the width, nor depth, nor cross-sectional area changes significantly along the length of the carpal tunnel $(6,28)$. The definitions of proximal and distal extends of the carpal tunnel might be responsible for this argument since the reported length of the carpal tunnel is $12.7 \pm 2.5 \mathrm{~mm}$ in one study and $21.7 \pm 6.05 \mathrm{in}$ the other $(7,28)$.

The median nerve: The median nerve is a mixed motor and sensory nerve; it is composed of branches from $\mathrm{C} 5$ through $\mathrm{T} 1$ spinal cord nerve roots. The sensory distribution is from radial three and half digits and part of the thenar eminence. The motor supply is to the radial two lumbricals and the muscles of the thenar eminence. The median nerve descends beneath the flexor digitorum superficialis, lying on the flexor digitorum profundus in the forearm, within 5 $\mathrm{cm}$ of the transverse carpal ligament, and then it becomes more superficial, situated between the tendons of the flexor digitorum superficialis and flexor carpi radialis (13). It lies behind and radial to the side of the palmaris longus tendon just before entering into the carpal tunnel. Approximately 5 $\mathrm{cm}$ proximal to the wrist crease, palmar cutaneous branch of the median nerve originates from the anterolateral or volar-radial quadrant of the median nerve under the radial margin of the flexor digitorum superficialis. It parallels the median nerve for a distance of $16-25 \mathrm{~mm}$, and then courses separately attaching itself to the antebrachial fascia under the ulnar border of the flexor carpi radialis tendon. Flexor carpi radialis enters its tunnel between the superficial and deep layers of the transverse carpal ligament while the palmar cutaneous nerve enters very short tunnel of its own, only nine millimeters long within the ligament, immediately medial to the tunnel of the flexor carpi radialis tendon $(6,38)$.

The median nerve is located between the flexor retianculum and the tendons of the middle finger flexor digitorum superficialis muscle in wrist extension (sublimis 2) (45). Flexion produces an anterior shift of the tendons toward the flexor retinaculum. The median nerve either becomes flattened against the flexor retianculum anterior to sublimis 2 or becomes interposed between individual flexor tendons, most commonly sublimis 2 and the flexor pollicis longus, but also sublimis tendons 3 and 4 . The flexed position places the median nerve, flexor tendons, and flexor retinaculum in closer proximity to each other. This anatomic crowding is consistent with the proposition that wrist flexion rather than extension as a predisposing mechanism to carpal tunnel syndrome, despite carpal tunnel pressure increases with both $(12,39)$.

The median nerve normally divides into six branches at the distal terminus of the flexor retinaculum. The six branches include the recurrent motor branch that innervates the 
abductor pollicis brevis, flexor pollicis brevis, opponens pollicis before dividing into its terminal sensory branches. There are proper digital nerves to the radial and ulnar sides of the thumb, and radial side of the index finger. These may emerge from the median nerve as a common digital nerve. The point of origin of the thenar branch is on the midpoint of a line drawn between the tubercle of the scaphoid and the distal end of the flexion crease of the thumb metacarpophalangeal joint (32). The penetration of the recurrent motor branch into the thenar musculature lies at the intersection of the cardinal line and the proximal continuation of the radial border of the long finger (11). Finally two common digital nerves branch to the second and third web spaces (44). The first lumbrical muscle is innervated by motor branches that originate from the radial proper digital nerve to the index finger; the second lubrical muscle is innervated by motor branches that originate from the second common digital nerve (13). Distal branches of the median nerve, especially the third common digital nerve (TCDN) is at risk during an open or endoscopic carpal tunnel release $(9,11,13)$.

A line drawn from the scaphoid to the radial cleft of the ring finger intersects the thenar flexion crease at about the location of the recurrent motor branch of the median nerve within the carpal canal; by flexing the long finger down adjacent to the ring finger, the tip of the long finger will touches the site in the thenar musculature where the thenar nerve arborizes. Since the origin of the recurrent motor branch within the carpal canal is along the thenar flexion crease, and incision to expose carpal canal or to incise the carpal transverse ligament should be ulnar to that crease and to the underlying ligament (16).

\section{The distal edge of the carpal tunnel}

The superficial palmar arch, a branch of the ulnar artery, along with the deep palmar arch, a branch of the radial artery supply blood to all fingers of the hand. The superficial palmar arch was reported to be $18.8 \pm 0.6 \mathrm{~mm}$ distal to the intersection of the distal transverse carpal ligament and the longitudinal line from the third web space (31). Injury to the superficial palmar arch can be avoided with knowledge of its location during open, limited incision or endoscopic carpal tunnel release. A communicating branch between the ulnar and median sensory nerves is described. This branch usually crosses the metacarpal space distal to the superficial palmar arch, but in some cases it may cross further proximally, just distal to the edge of the transverse carpal ligament. This position makes it vulnerable to injury during carpal tunnel release (24). The hook of the hamate marks the ulnar edge of the flexor retinaculum. The deep motor branch of the ulnar nerve passes next to the ulnar side of the hook of the hamate. If the ulnar side of the flexor retinaculum is divided in an attempt to avoid the median nerve, the motor branch of the ulnar nerve may be injured. If distal retinaculum is divided in a radial direction care must be taken with the third common digital nerve (11).

\section{DISCUSSION}

Varying results have been reported on the prevalence of median nerve anomalies. Median nerve variations are well described due to its diagnostic and surgical importance $(1,9,10,21)$. Lanz classified the variations of the course of the median nerve into four groups: Group O: Extraligamantous thenar branch (standard anatomy), Group I: Variations in the course of the thenar branch, Group II: Accessory branches of the median nerve at the distal portion of the carpal tunnel, Group III: High divisions of the median nerve, Group IV: Accessory branches proximal to the carpal tunnel (21). Group $\mathrm{I}$ is divided into four subgroups. Group I a, the motor branch of the median nerve starts beneath the transverse ligament and then bends around its distal edge (subligamentous). In Group I b, the motor branch originates from the radial side of the median nerve and then passes through the transverse ligament (transligamentous). In Group I c, the motor branch arises from the ulnar side of the median nerve. In Group Id, the motor branch bends around the distal edge of the ligament (supraligamentous) (Figure 3). The transligamentous course is of great clinical significance because of the possibility of compression within the retinacular fibers (16).

It was concluded that the recurrent motor branch found to be originating from extreme radial aspect of the median nerve in $60 \%$ of the dissections, in $22 \%$ from the central anterior aspect, and between the extreme radial - anterior and the central aspect of the median nerve in the remaining 18\% (44). Hurwitz et al. reported an anomalous origin of the recurrent motor branch in $21 \%$ of 80 hands. He observed multiple motor branches in $12.5 \%$ of the hands. He draw attention to an additional anomaly in seven patients (9\%); the motor branch arose from the anterior surface of the median nerve, turning ulnar and crossing the distal edge of the flexor retinaculum under the cover of a hypertrophic abductor pollicis brevis muscle. The nerve can easily be injured during splitting of the flexor retinaculum with this anomaly (14). The nerve should be approached from ulnar side to minimize risk of lesion. In a study, it was founded that the recurrent motor branch of the median nerve passes through a separate tunnel immediately prior to entering the thenar muscles in $56 \%$ of the dissections (23).

Group II is characterized by the true duplications of the thenar branch and additional thin sensory branches, which originates from the palmar or ulnar side of the median nerve. Falconer and Spinner noted duplication of the recurrent motor nerve in two of ten specimens examined, in which a transligamantous branch supplied the abductor pollicis brevis and the opponens, and in separate extraligamantous branches supplying the superficial flexor pollicis brevis (10). Individual variations such as an accessory branch distal to the carpal tunnel (Lanz group II) with the third common digital nerve (terminal branches) originating proximal to the distal edge of the TCL have also been reported (8).

Group III may be further divided in to three subgroups according to the absence (Group III a) or the presence of a 


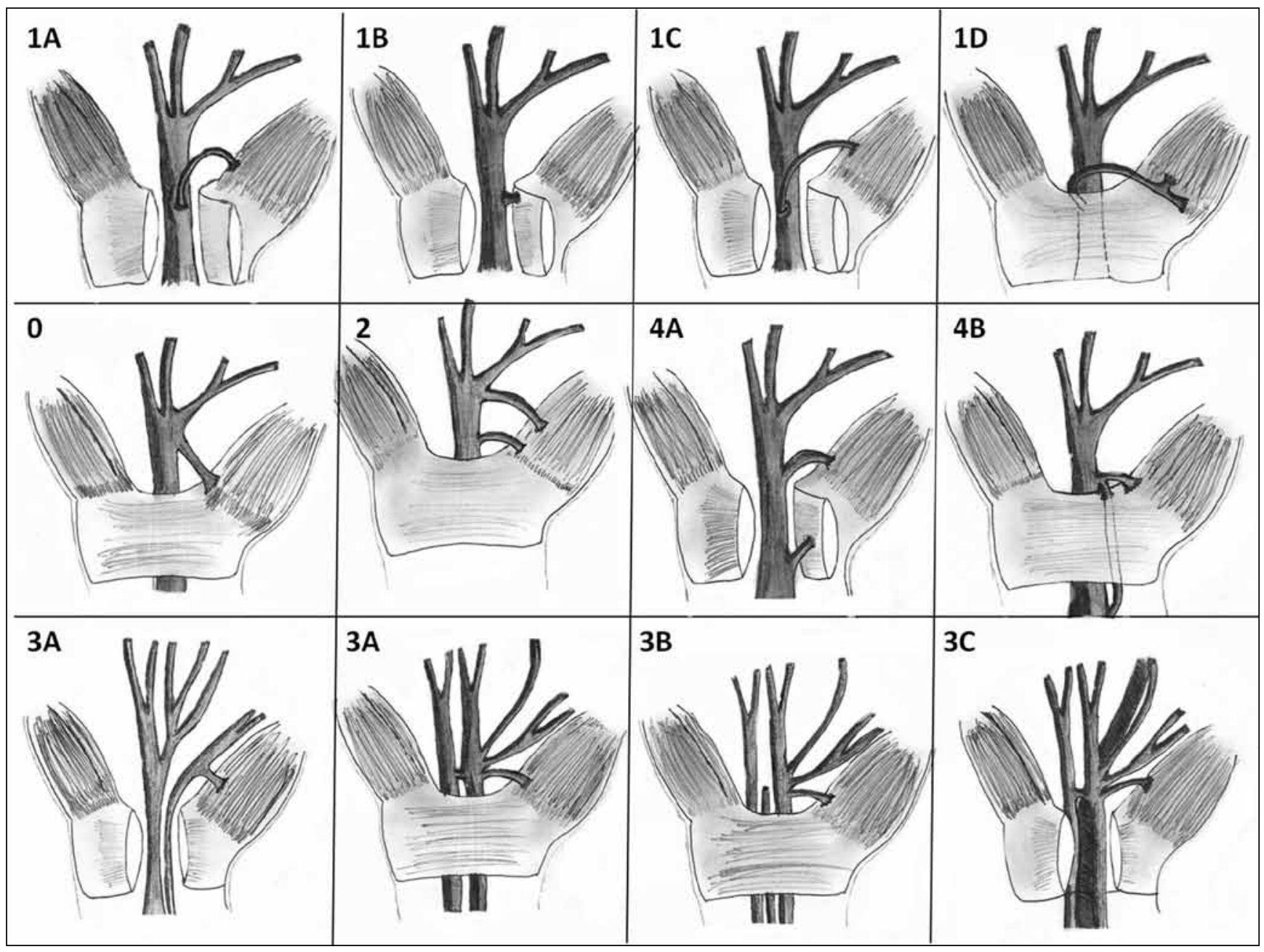

Figure 3: Lanz classification of the median nerve anatomical variations at the wrist. Group I, Thenar branch variations; 1A: subligamentous; 1B: transligamentous; 1C: ulnarwards; 1D: supraligamentous. Group 0, extraligamentous thenar branch. Group II, distal accessory thenar branch. Group IV, proximal accessory thenar branch; 4A: running directly in the thenar muscles; 4B: joining another branch. Group III, high division of the median nerve; 3A: without an artery of muscle; 3B: with artery; 3C: with lumbrical muscle.

median artery (Group III b) or an accessory lumbrical muscle (Group III c) between the two branches of the proximally divided median nerve. A high division of median nerve in which the radial branch passing through its own compartment of the carpal tunnel was described by Amadio (2).

There are accessory branches leaving median nerve proximal to the carpal tunnel in Group IV. Accessory thenar branch may run directly in the thenar muscles (Group IV a), or it may join another motor branch first (Group IV b).

Lanz at al. reported 12\% (29 hands) variations in the course of the median nerve in $\mathbf{2 4 6}$ hands. The motor nerve branches from the median nerve distal to the end of the flexor retinaculum (extraligamantous), doubled back to innervate the thenar eminance in $46 \%$ of cases, and branches from the median nerve under the flexor retinaculum (subligamantous) in $31 \%$ of the cases, in $23 \%$ of cases, the motor branch perforates the retinaculum passing through its own tunnel (transligamantous) to the thenar musculature (21). Accessory branches of the median nerve in the distal portion of the carpal tunnel (group II) were found in 18 hands (7\%), high division of the median nerve (group III) in 7 hands (3\%), and 4 hands (1.6\%) had accessory branches proximal to the carpal tunnel (group IV) (21). On the other hand, Lindley and Kleinert observed $1 \%$ ( 5 hands) with median nerve or its palmar cutaneous branch or motor branch anomalies during the course of 526 elective carpal tunnel releases in one surgeon's practice (22). Furthermore, Tountas CP et al. reported on 821 median nerves undergoing surgery to treat CTS. Ninety-two cadaver median nerves were also dissected to document the incidence of variations within the carpal canal. The combined incidence of anomalies at operation (Lanz groups I to IV) was $9.8 \%$ and $18 \%$ in the cadaver series. Their $1.42 \%$ of cases fit into Lanz group I, whereas Poisel reported 54\%. The difference 
could not be explained and they concluded further studies were needed (41).

Stancic et al. reported that 48 hands showed standard anatomy in exploration of 100 hands. Seventeen hands were in Lanz Group 1A, 16 hands were in Lanz Group 1B, 5 hands were in Lanz Group 1C, 2 hands were in Lanz Group 1D, 7 hands were in Lanz Group 2, 1 hand was in Lanz Group 3B, and 4 hands were in Lanz Group 4A (34).

Olave et al. reported that normal anatomy of the recurrent branch of the median nerve was observed $48.3 \%$ of 60 cases, $18.3 \%$ of the cases were in Lanz Group 1A, 15\% in Lanz Group $1 \mathrm{~B}, 16.7 \%$ of the cases in Lanz Group 1C, an accessory thenar branch was found in 23 cases, $38.3 \%$ of the total cases (Lanz Group II) (26).

In a series of 110 patients who underwent open carpal surgery, Beris et al. reported variations of median nerve at the wrist in 11 patients (10\%). 3 cases were in Lanz Group 1A (2.7\%), 2 were in Lanz Group 1C (1.8\%), 3 in Lanz Group 2 (2.7\%), and 2 cases in Group 3B (1.8\%). Palmar cutaneous branch of the median nerve was seperated from the radial aspect of the nerve few milimeters distal to the proximal border of the transverse carpal ligament in one patient. This variation poses a special risk of iatrogenic injury during either endoscopic or open carpal tunnel release (4).

Falconer et al. evaluated anatomic variations in the motor and sensory supply of the thumb in ten preserved cadaver forearms.The motor branch divided distal to the distal edge of the ligament in three (Lanz Group 0), divided subligamentously to recurve proximally in one (Lanz Group $1 \mathrm{~A})$, perforated the ligament to travel in a separate tunnel in six specimens (Lanz Group 1B). Accessory motor branches at the level of the distal edge of the transverse carpal ligament was seen in two specimens (Lanz Group 2) (10).

Johnson and Shrewsbury found in 8 dissections out of 10 thenar branch of the median nerve entered a definite tunnel of its own and crossed the transverse carpal ligament (16). High results recorded by Johnson \& Shrewsbury (1970) and Falconer \& Spinner (1985) may be result of including in the flexor retinaculum part of the fibrotendinous tissue of the thenar muscles (26).

In sixty cadaver hands, Alizadeh et al. reported $78 \%$ median nerve variations. In 28 (47\%) hands recurrent nerve ran an extraligamentous course (Lanz Group 0), subligamentous in $17(28.3 \%)$ (Lanz Group 1A), transligamentous in $7(11.7 \%)$ (Lanz Group 1B). The recurrent branch originated from the ulnar side in 7 (11.7\%) cases (Lanz Group 1C) (1).

Steinberg et al. dissected both hands of 23 cadavers. The nerve was found to course in a normal manner in 33 of 46 (71.7\%) upper extremities. The most common variant that he observed was the recurrent nerve piercing the carpal ligament 2 to $4 \mathrm{~mm}$ proximal to the distal end of the tunnel in 13 hands (28.3\%). An additional branch in the proximal part of the tunnel was found in $10(21.7 \%)$ hands, following a similar route to that in Lanz Group IV (36). Kozin dissected 101 fresh frozen cadavers, in $7 \%$ of the cases recurrent branch of the median nerve passed through the transverse carpal ligament, in $74 \%$ of the cases recurrent nerve passed distal to the TCL through separate obliquely oriented fascia and in $19 \%$ of the cases it passed distal to the TCL but did not pass through the obliquely oriented fascia. He concluded that the transligamentous branch is uncommon and the reported high incidance of branches passing through the TCL can be explained by mistakenly combining recurrent nerves passing through the obliquely oriented fascia with the recurrent nerves passing through TCL (19).

An accessory branch of the recurrent nerve was identified, in $31.6 \%$ of the 60 cadaver hands (1). It had proximal origin in $13.6 \%$ of cases, distal origin in $13.6 \%$, and both proximal and distal origins in $5.1 \%$ of the cases (1). Additionally, Steinberg et al. dissected 46 hands and in 10 hands they found an accessory branch of the median nerve piercing the lateral carpal ligament 3 to $6 \mathrm{~mm}$ distal to the proximal edge of the tunnel. The branch was approximately $1 \mathrm{~mm}$ wide, leaving the radial or volar side of the median nerve at a right angle. They considered it as a sensory branch due to its size and course (36).

High bifurcation of the median nerve in the forearm has been reported by several authors. If care is not taken to do TCL division under direct vision it is possible to cut the ulnar part of the divided median nerve $(17,21,43)$.

Median nerve variations reported in the literature are summarized in Table I.

The position and course of the median nerve within the carpal tunnel also shows some variations (Figure 4).

a. The nerve passes dorsal to the flexor retinaculum to the palm without curving in two thirds of the cases.

i. The median nerve is shifted to the radial side of the carpal tunnel in $43.3 \%$

ii. Below the middle of the flexor retinaculum in $21.7 \%$

iii. It is shifted to the ulnar side in $1.7 \%$.

b. Median nerve curves within the carpal tunnel.

i. Diverging to the radial in $21.6 \%$ of the cases.

ii. Diverging to the ulnar side in $11.7 \%$ of the cases (32)

Anatomic variations for the origin of the third common digital nerve were grouped into three specific types: Type I originating proximal to the distal edge of the transverse carpal ligament (TCL) (15\%), type II originating distal to the TCL but proximal to the superficial palmar arch (70\%), and type III originating distal to the TCL and at or distal to the superficial palmar arch (15\%). Type I variation is especially at risk for it originates in the carpal tunnel, but an oblique course of all variations to the TCDN makes them all susceptible to injury due to the longitudinal direction of the incision to divide the $\operatorname{TCL}(9,17)$. Open carpal tunnel release has the benefit of direct visualization of the median nerve and its branches. Although 


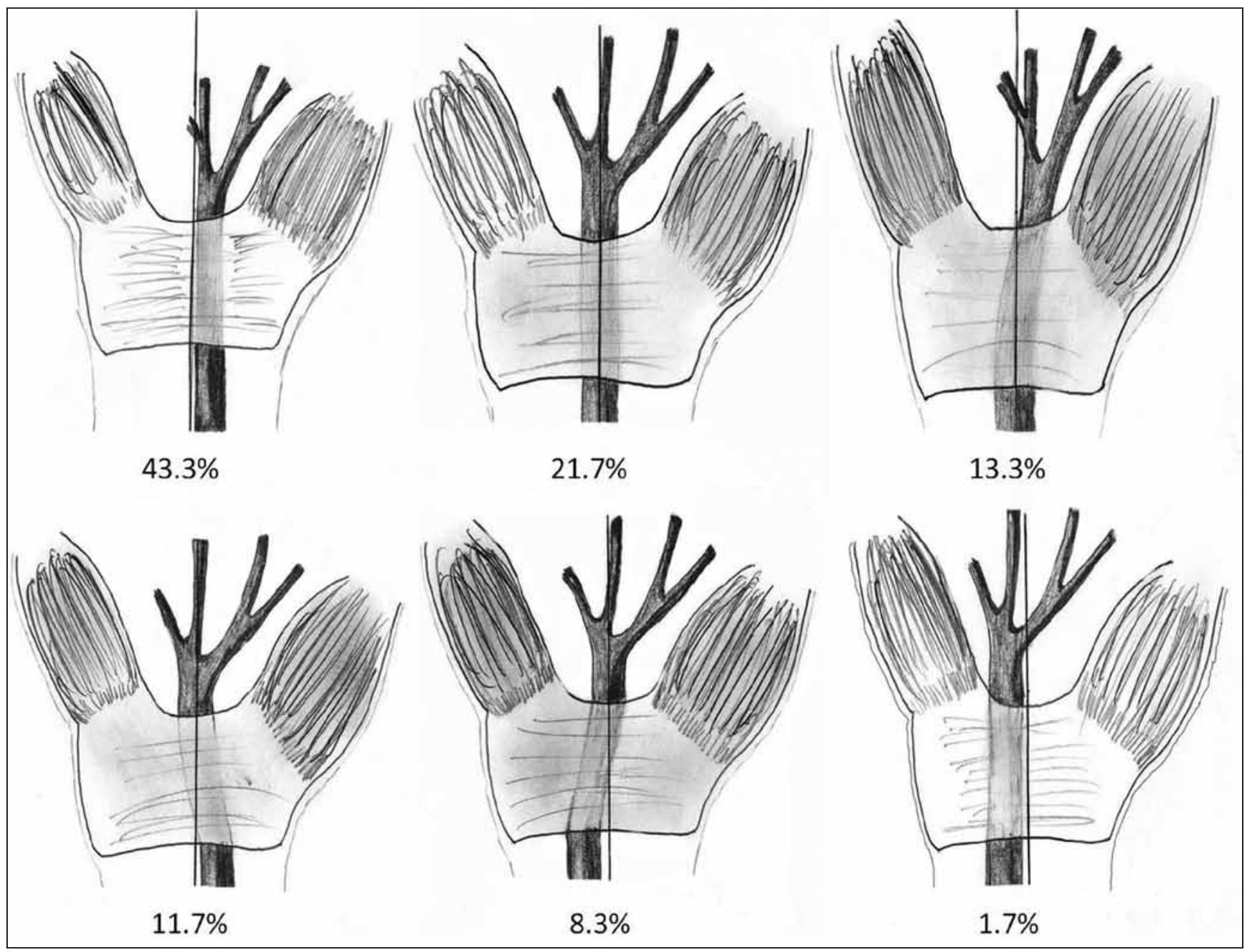

Figure 4: Variations in the position and the course of the median nerve.

endoscopic CTR with single proximal incision (Agee) has limited visualization, injury to all types of TCDN origins can be avoided with this technique. An unaware surgeon could transect, especially Types 1 and 2 of TCDN origin, because they lie under or just distal to the TCL.

Communications between the median and ulnar nerve in the forearm is common, its incidence is reported to be about 10 to $23 \%(18,30,37)$. They are known as Martin - Gruber anastomosis after it was first described by Martin in 1763 and then later by Gruber. They were reported rarely in the distal forearm and in the palm, between the recurrent branch of the median and the deep branch of the ulnar nerve $(18,30,37)$. The majority of these connections cross over from the median nerve to the ulnar nerve. Connections from ulnar to median nerve in the forearm are extremely rare $(18,30,37)$. The rarity of these connections indicates that they are anomalies. They are referred to as "reverse Martin - Gruber anastomosis" (37). These anastomoses cause changes in motor conduction studies, and in the presence of carpal tunnel syndrome, it may result in unusual findings in evoked muscle potentials. Partial or total sparing of thenar muscles is possible from the effects of compression neuropathy of carpal tunnel syndrome with the presence of these connections. They are also suggested as causes for unusual motor losses of muscles in the hand after peripheral nerve lesions $(15,18,37)$.

Variations in Martin - Gruber anastomosis can be classified by patterns and types. Pattern I comprises cases with one anastomotic branch, and Pattern II those with two anastomotic branches. Types $\mathrm{a}, \mathrm{b}$, and $\mathrm{c}$ are subdivisions depending on the level of origin of the anastomosis from the median nerve. Type a originates from the branch of the median nerve to the superficial forearm muscles. Type $b$ originates from the median nerve itself and Type $\mathrm{c}$ from the anterior interosseous nerve $(18,25,30,37,40)$. (Table II).

These reports are in part responsible for the shift away from the previously popular (29) short transverse incision when surgery is necessary for the carpal tunnel syndrome, because these anomalous nerve branchings are at jeopardy in the process of a blind release of the transverse carpal ligament (10). 
Table I: Median Nerve Variations in the Literature

\begin{tabular}{|c|c|c|c|c|c|c|c|}
\hline & Alizadeh & Lanz & Steinberg & Olave & Stancic & Beris & Falconer \\
\hline Extraligamantous (Lanz Group 0) & 46.6 & 46 & - & 48.3 & 48 & - & 30 \\
\hline Subligamantous (Lanz Group 1A) & 28.3 & 31 & - & 18.3 & 17 & 2.7 & 10 \\
\hline Transligamantous (Lanz Group 1B) & 11.7 & 23 & 28.3 & 15 & 16 & & 60 \\
\hline From ulnar side (Lanz Group 1C) & 11.7 & - & & 16.7 & 5 & 1.8 & \\
\hline Supraligamantous (Lanz Group 1D) & - & - & - & - & 2 & - & \\
\hline $\begin{array}{l}\text { Accessory branches of the median nerve at the } \\
\text { distal carpal tunnel (Lanz Group 2) }\end{array}$ & 18.3 & 7.3 & & 38.3 & 7 & 2.7 & 20 \\
\hline $\begin{array}{l}\text { High division of the median nerve } \\
\text { (Lanz Group 3) }\end{array}$ & & 2.8 & & & & & \\
\hline \multicolumn{8}{|l|}{ Median artery absent (Lanz Group 3A) } \\
\hline Median artery present (Lanz Group 3B) & & & & & 1 & 1.8 & \\
\hline \multicolumn{8}{|l|}{$\begin{array}{l}\text { Accessory lumbrical muscle present (Lanz Group } \\
3 C)\end{array}$} \\
\hline $\begin{array}{l}\text { Accessory branches of the median nerve at the } \\
\text { proximal carpal tunnel (Lanz Group 4) }\end{array}$ & 18.3 & 1.7 & & & & & \\
\hline $\begin{array}{l}\text { Accessory thenar branch running directly in the } \\
\text { then ar muscles (Lanz Group 4A) }\end{array}$ & & & 21.7 & & 4 & & \\
\hline $\begin{array}{l}\text { Accessory thenar branch joining another motor } \\
\text { branch first (Lanz Group 4B) }\end{array}$ & & & & & & & \\
\hline
\end{tabular}

Table II: Variations in Martin - Gruber Anastomosis

\begin{tabular}{|c|c|c|c|c|c|}
\hline & Rodrigez-Niedenführ & Kazakos & Taams & Thomson & Nakashima \\
\hline $\begin{array}{l}\text { Pattern } 1 \\
\text { One anastamotic branch }\end{array}$ & 89.5 & 100 & 100 & 100 & 95.7 \\
\hline $\begin{array}{l}\text { Type } 1 \\
\text { (originates from the superficial median } \\
\text { nerve to the superficial forearm muscles) }\end{array}$ & 47.3 & 7 & 30.8 & 3 & 34.8 \\
\hline $\begin{array}{l}\text { Type } 2 \\
\text { (median nerve itself) }\end{array}$ & 10.6 & 7 & & 19 & 4.3 \\
\hline $\begin{array}{l}\text { Type } 3 \\
\text { (anterior interosseous nerve) }\end{array}$ & 31.6 & 87 & 69.2 & 78 & 56.5 \\
\hline $\begin{array}{l}\text { Pattern } 2 \\
\text { Two anastamotic branch }\end{array}$ & 10.5 & 0 & & & 4.3 \\
\hline
\end{tabular}

\section{CONCLUSION}

Anatomic variations of the median nerve occur frequently and may lead to diagnostic confusion and present surgical risks if not recognized. Successful diagnosis and treatment of median nerve entrapment syndromes require awareness of possible involved sites and a detailed knowledge of related anatomy.

\section{REFERENCES}

1. Alizadeh K, Lahiji F, Phalsaphy M: Safety of carpal tunnel release with a short incision. A cadaver study. Acta Orthop Belg 72(4):415-419, 2006

2. Amadio PC: Bifid median nerve with a double compartment within the transverse carpal canal. J Hand Surg Am 12(3): 366-368, 1987 
3. Aydin K, Cokluk C, Piskin A, Kocabicak E: Ultrasonographically checking the sectioning of the transverse carpal ligament during carpal tunnel surgery with limited uni skin incisions. Turk Neurosurg 17(3):219-223, 2007

4. Beris $A E$, Lykissas $M G$, Kontogeorgakos VA, Vekris MD, Korompilias AV: Anatomic variations of the median nerve in carpal tunnel release. Clin Anat 21(6):514-518, 2008

5. Bezerra AJ, Carvalho VC, Nucci A: An anatomical study of the palmar cutaneous branch of the median nerve. Surg Radiol Anat 8(3):183-188, 1986

6. Bower JA, Stanisz GJ, Keir PJ: An MRI evaluation of carpal tunnel dimensions in healthy wrists: Implications for carpal tunnel syndrome. Clin Biomech (Bristol, Avon) 21(8):816-825, Epub 2006

7. Cobb TK, Dalley BK, Posteraro RH, Lewis RC: Anatomy of the flexor retinaculum. J Hand Surg Am 18(1):91-99,1993

8. Demircay E, Kabatas S, Cansever T, Yilmaz C: An anatomical variation of the third common digital nerve and recurrent motor branch of the median nerve. Neurol India 57(3): 337-339, 2009

9. Engineer NJ, Hazani R, Mowlavi A, Neumeister MW, Lee WPA, Wilhelmi BJ: Variations in the anatomy of the third common digital nerve and landmarks to avoid injury to the third common digital nerve with carpal tunnel release. Eplasty 8 e:51, 2008

10. Falconer D, Spinner $M$ : Anatomic variations in the motor and sensory supply of the thumb. Clin Orthop Relat Res 195:83-96, 1985

11. Friedman $\mathrm{AH}$ : Surgical anatomy of the carpal tunnel. Neurosurg Focus 15; 3(1):e1, 1997

12. Gelberman RH, Szabo RM, Mortensen WW: Carpal tunnel pressures and wrist position in patients with colles' fractures. J Trauma 24(8):747-749, 1984

13. Goss CM: The peripheral nervous system. In: Goss CM ed. Gray's Anatomy. 29th merican edition, Philadelphia, PA: Lea \& Febiger, 1973:903-1036

14. Hurwitz PJ: Variations in the course of the thenar motor branch of the median nerve. J Hand Surg Br 21(3):344-346, 1996

15. lyer V, Fenichel GM: Normal median nerve proximal latency in carpal tunnel syndrome: A clue to coexisting MartinGruber anastomosis. J Neurol Neurosurg Psychiatry 39(5): 449-452, 1976

16. Johnson RK, Shrewsbury MM: Anatomical course of the thenar branch of the median nerve-usually in a separate tunnel through the transverse carpal ligament. J Bone Joint Surg Am 52(2):269-273, 1970

17. Jeon IH, Kim PT, Park IH, Park BC, Ihn JC: High bifurcation of median nerve at the wrist causing common digital nerve injury in endoscopic carpal tunnel release. J Hand Surg $\mathrm{Br}$ 27(6):580-582, 2002

18. Kazakos KJ, Smyrnis A, Xarchas KC, Dimitrakopoulou A, Verettas DA: Anastomosis between the median and ulnar nerve in the forearm. An anatomic study and literature review. Acta Orthop Belg 71(1):29-35, 2005
19. Kozin $\mathrm{SH}$ : The anatomy of the recurrent branch of the median nerve. J Hand Surg Am 23(5):852-858, 1998

20. Kureshi SA, Friedman AH: Carpal tunnel release: Surgical considerations. Techniques in Neurosurgery 6(1):5-13, 2000

21. Lanz U: Anatomical variations of the median nerve in the carpal tunnel. J Hand Surg Am 2(1):44-53, 1977

22. Lindley SG, Kleinert JM: Prevalence of anatomic variations encountered in elective carpal tunnel release. J Hand Surg Am 28(5):849-855, 2003

23. Mackinnon SE, Dellon AL: Anatomic investigations of nerves at the wrist: I. Orientation of the motor fascicle of the median nerve in the carpal tunnel. Ann Plast Surg 21(1):32-35, 1988

24. May JW Jr, Rosen H: Division of the sensory ramus communicans between the ulnar and median nerves: $A$ complication following carpal tunnel release. A case report. J Bone Joint Surg Am 63(5):836-838, 1981

25. Nakashima T: An anatomic study on the Martin-Gruber anastomosis. Surg Radiol Anat 15(3):193-195, 1993

26. Olave E, Prates JC, Gabrielli C, Pardi P: Morphometric studies of the muscular branch of the median nerve. J Anat 189 (Pt 2):445-449, 1996

27. Okutsu I: Operative treatment for carpal tunnel syndrome. Brain Nerve 59(11):1239-1245, 2007

28. Pacek CA, Tang J, Goitz RJ, Kaufmann RA, Li ZM: Morphological analysis of the carpal tunnel. Hand 5:77-81, 2010

29. Phalen GS: The carpal tunnel syndrome: Seventeen years' experience in diagnosis and treatment of six hundred fiftyfour hands. J Bone Joint Surg Am 48(2):211-228, 1966

30. Rodriguez-Niedenführ M, VazquezT, Parkin I, Logan B, Sañudo JR: Martin-Gruber anastomosis revisited. Clin Anat 15(2):129134,2002

31. Sacks JM, Kuo YR, Mclean K, Wollstein R, Lee WP: Anatomical relationships among the median nerve thenar branch, superficial palmar arch, and transverse carpal ligament. Plast Reconstr Surg 120(3):713-718, 2007

32. Schmidt HM: Normal anatomy and variations of the median nerve in the carpal tunnel. In: Luchetti R, Amadio P, Ed. Carpal tunnel syndrome. Verlag Berlin Heidelberg: Springer, 2007: 13-20

33. Singer G, Ashworth CR: Anatomic variations and carpal tunnel syndrome: 10-year clinical experience. Clin Orthop Relat Res 392:330-340, 2001

34. Stancić MF, Eskinja N, Stosić A: Anatomical variations of the median nerve in the carpal tunnel. Int Orthop 19(1):30-34, 1995

35. Steinberg DR, Szabo RM: Anatomy of the median nerve at the wrist. Open carpal tunnel release-classic. Hand Clin 12(2):259-269, 1996

36. Steinberg EL, Luger E, Taitz C, Arensburg B: Anatomic variant of the median nerve in the carpal tunnel. Clin Orthop Relat Res (352):128-130, 1998

37. Taams KO: Martin-Gruber connections in South Africa. An anatomical study. J Hand Surg Br 22(3):328-330, 1997 
38. Taleisnik J: The palmar cutaneous branch of the median nerve and the approach to the carpal tunnel. An anatomical study. J Bone Joint Surg Am 55(6):1212-1217, 1973

39. Tanzer RC: The carpal-tunnel syndrome: A clinical and anatomical study. J Bone Joint Surg Am 41-A(4):626-634, 1959

40. Thomson A: Third Annual Report of Committee of Collective Investigation of Anatomical Society of Great Britain and Ireland for the Year 1891-92. J Anat Physiol 27(Pt 2):183-194, 1893

41. Tountas CP, Bihrle DM, MacDonald CJ, Bergman RA: Variations of the median nerve in the carpal canal. J Hand Surg Am 12(5 Pt 1):708-712, 1987
42. Wertsch JJ, Melvin J: Median nerve anatomy and entrapment syndromes: A review. Arch Phys Med Rehabil 63(12):623-627, 1982

43. Wood VE, Frykman GK: Unusual branching of the median nerve at the wrist. A case report. J Bone Joint Surg Am 60(2):267-268, 1978

44. Yugueros $P$, Berger RA: Anatomy of the carpal tunnel. In: Luchetti R, Amadio P, Ed. Carpal tunnel syndrome. Verlag Berlin Heidelberg: Springer, 2007: 10-12

45. Zeiss J, Skie M, Ebraheim N, Jackson WT: Anatomic relations between the median nerve and flexor tendons in the carpal tunnel: MR evaluation in normal volunteers. AJR Am J Roentgenol 153(3):533-536, 1989 